\title{
APROXIMAÇÃO SOBRE O PENSAMENTO DE UMA MÃE DE SANTO E A EMANCIPAÇÃO FEMININA
}

\author{
Tânia Mara Campos de Almeida ${ }^{1}$ \\ Guilherme Dantas Nogueira ${ }^{2}$ \\ DOI 10.26512/revistacalundu.v4i1.32236
}

Mãe Patrícia de Oyá Timboá, ou völva Annan Wollo - como mais recentemente vem se identificando e sendo identificada por esse nome sagrado, lhe atribuído por seu guia -, é uma figura encantadora. Habitante de Ramos Mejía, província de Buenos Aires (Argentina), é uma típica liderança afrorreligiosa argentina: reúne e coordena sua comunidade religiosa de sua casa, que é ao mesmo tempo terreiro e residência, além da morada das cabeças de suas/seus filhas/os de santo; vive em harmonia e comunhão com suas entidades e, em particular, com seu referido mentor espiritual, a quem chama, respeitosamente, de Viejo - conheceu-o como Exú Destranca Rua nos cultos afrorreligiosos. Conhece a fundo os preceitos da Quimbada, praticada no Rio Grande do Sul (Brasil) e que migrou para a Argentina; da mesma forma, é sabedora dos preceitos do Batuque e da Umbanda.

Atende e assiste sua comunidade com os elementos necessários, oriundos da linguagem sagrada e ritual afrorreligiosa que tem à sua disposição, sempre posta a bom e solidário uso. A esse arsenal, cabe dizer, acrescentam-se também conhecimentos e resgates de antigos e femininos cultos pagãos germânicos, resgatados e incluídos em seu terreiro, com apoio de suas entidades. Em um ocidente marcado por ideias de cartesianismos, purezas e intolerâncias, essa grande líder religiosa nos lembra como a união de povos e crenças é potente.

O primeiro contato com Anna Wollo ocorreu em março de 2013, quando o então estudante de mestrado em Ciências Sociais da Universidade de Brasília, Guilherme Dantas Nogueira, foi à sua casa fazer pesquisa de campo. Guilherme buscava entender como o Estado argentino se relacionava com as comunidades de terreiro daquele país, algo em que a paciente e letrada mãe de santo podia ajudar. De algumas conversas e

\footnotetext{
1 Professora Adjunta IV do Departamento de Sociologia da Universidade de Brasília. E-mail: taniamaraunb@gmail.com

${ }^{2}$ Tata Kambondo Mub'nzazi, da Cabana Senhora da Gória - Nzo Kuna Nkos'i. Doutor em Sociologia e pesquisador colaborador do Departamento de Sociologia da Universidade de Brasília. Integrante fundador do Grupo Calundu. E-mail: guidantasnog@gmail.com
} 
observações diretas, iniciou-se uma forte amizade - com Mãe Patrícia e com toda a sua família religiosa - que perdura até o presente. Não só isso, Guilherme se entende como parte da família daquela casa de santo, sem prejuízos ao fato de ser ogan do Candomblé e filho de Umbanda de sua própria casa brasileira.

Ademais, Guilherme se relaciona com Anna Wollo em uma condição que identifica como sendo a de aprendiz diante de uma mestra. Esta lhe ofereceu elementos variados para seus trabalhos acadêmicos e, além disso, para a sua própria formação como afrorreligioso. Haja vista que os Calundus do passado eram a própria expressão da pluralidade, tendo suas linguagens rituais sido absorvidas pelos Calundus do presente - que seguem plurais. Neste sentido, Candomblé, Batuque, Umbanda e Quimbanda são religiões irmãs, com alta porosidade entre si, e o aprendiz ogan Guilherme, oriundo da tradição de Angola, sempre aprende muito com a mestra Mãe Patrícia.

Tendo, portanto, nascido ${ }^{3}$ uma grande amizade, Anna Wollo, sua família de santo e Guilherme jamais perderam contato. Pelo contrário, seguiram mantendo diálogos frequentes por meio da Internet, redes sociais e aplicativos de comunicação. Guilherme, em particular, seguiu aprendendo com Mãe Patrícia. E sua relação e contato tiveram peso quando o pesquisador, já mestre, escolheu o tema de sua tese de doutorado: a percepção das mães de santo sobre o Estado-nação.

Essa pesquisa teve como foco o Brasil, não mais a Argentina, mas isso não impediu que os aprendizados com mãe Patrícia fossem recuperados em vários momentos da tese. Mães de santo, como se sabe, são figuras transnacionais por excelência. Da maneira como são compreendidas no Brasil, formaram-se na diáspora, inteligente e politicamente resgatando, mantendo e atualizando saberes religiosos africanos, sincretizados com saberes religiosos ameríndios, formatados em diálogo forçado com o catolicismo português. Ademais, reuniram ao papel de lideranças religiosas aquele outro de líderes político-comunitárias. Historicamente, formaram e mantiveram suas comunidades de terreiro nas franjas periféricas brasileiras, prestando apoios às suas vizinhanças que eram negados pelos colonizadores desde longa data dinâmica que se repete, atualizada, no presente colonial/moderno (NOGUEIRA, 2019).

Sendo Patrícia uma mãe de santo iniciada nas tradições afrorreligiosas brasileiras, ela repete na periferia de Buenos Aires o importante papel social exercido pelas mães brasileiras: aquele do acolhimento, da escuta afetiva, do cuidado e da

\footnotetext{
${ }^{3}$ Guilherme e Patrícia entendem que sua ligação transcende o tempo e vidas. São amigos desde vidas passadas.
} 
bondade amorosa, englobante, plural, autônomo, resistente à, ao mesmo tempo que dialeticamente marcado pela, colonial modernidade latino-americana. Nesse sentido, para Guilherme, dialogar sobre a experiência daquela mãe de santo como material de pesquisa para sua tese foi também uma oportunidade riquíssima. Essa oportunidade veio a se concretizar em novembro de 2018, quando Guilherme foi à Buenos Aires participar, junto com a sua orientadora à época Tânia Mara Campos de Almeida, do $I V$ Congreso de Estudios Poscoloniales y VI Jornadas de Feminismo Poscolonial.

Junto com Tânia, Guilherme voltou a Ramos Mejía e puderam dialogar, por horas, sobre o ofício de mãe de santo com Patrícia. Tânia, naquele dia, também se aproximou dessa destacada pessoa, e iniciou com ela uma amizade que também rende diálogos até hoje. Contatos frequentes vêm ocorrendo entre elas sobre assuntos diversos, como a situação dos nossos países, o avanço da epidemia do COVID-19, questões pessoais e outros.

Em particular, chamou a atenção de Tânia o pedido de Patrícia para que comentasse o texto da mãe pequena do terreiro, Skuld Wollo (Maria Azul Di Baja), publicado na Revista Calundu v.3 n.2 (Jul-Dez 2019): (Re) Existência que Continua, intitulado "Um Relato Kimbandista, Umbandista e Batuqueiro da Argentina" (BAJA, 2019). Em linhas gerais, trata-se de um relato sobre sua própria experiência afrorreligiosa: como se tornou, ademais de quimbandista, umbandista e batuqueira, mulher adulta, cônscia de si e lutadora por sua autonomia, a partir do contato e da relação que desenvolveu com as entidades da sua mãe de santo, em particular com Dona Maria Padilha, a pomba-gira da mãe Patrícia. De modo específico, o texto impressiona pela honestidade, afetividade e singeleza ao narrar a força de transformação pessoal que a religiosidade afro-brasileira produz na autora, estimulada pela comunidade religiosa formada ao redor da mãe Patrícia e das suas entidades. É comovente ver como ensinamentos, gestados a partir da história do nosso povo, atravessaram fronteiras nacionais e conseguem levar o bem-estar e a esperança a vários lugares distantes, cativando, inclusive, jovens à luta pela igualdade entre os gêneros em outros contextos locais e nacionais.

Da parte de Patrícia, o texto lhe havia sido muito interessante e revelador, especialmente por vir a ter claro que as palavras de sua entidade, Maria Padilha, deram o pontapé na formação feminista da mãe pequena. Ela, até então, não havia alcançado essa dimensão importante a respeito das sementes que as entidades plantam nas mentes e nos corações das pessoas que as procuram por seu intermédio. Ela percebeu, 
nitidamente, que as entidades possuem tarefas ainda mais profundas que orientar o diaa-dia e ajudar a resolver conflitos, como também possuem a capacidade de contribuir com o desvelamento da essência das personalidades, atuando para o encontro das pessoas com o sentido de suas vidas. Compreender que as suas entidades eram catalizadoras de um bem maior, a partir da leitura de um texto de uma integrante muito próxima a ela e participativa de sua comunidade, colocou nova luz e responsabilidade em seu grandioso papel de liderança religiosa.

Esse impacto vivido por Patrícia causou curiosidade à Tânia, em saber mais sobre esse processo de uma mãe de santo ir se dando conta da magnitude das suas entidades na interação com as pessoas que com elas vão se aconselhando e dialogando. Como uma entidade e a própria mãe de santo vão se descobrindo em interações e, assim, vão se tornando também epistemólogas ao darem nomes, elaborarem termos e interpretações do mundo em processos de sociabilidade e subjetividade que se põem em curso conjuntamente e, ao mesmo tempo, individualmente para cada uma? Como o vínculo que atrela a mãe de santo a suas entidades possui uma dimensão de mistério, que vai sendo desvelada no decorrer da vida, trazendo surpresas e proporcionado o alcance de novos degraus no conhecimento do humano e da divindade? Como uma entidade, que viveu em outra data, pode se conectar com princípios de movimentos sociais atuais, conforme o feminismo, mesmo que não seja exatamente assim por ela nomeado? Como a mãe de santo ocupa, cada vez mais, o lugar de filósofa da sua crença e vivência religiosa no mundo marcado pelo patriarcado, podendo comunicá-la a partir de sua reflexão autoral feminina?

Mãe Patrícia foi, então, convidada para escrever sobre essas indagações e sua experiência no presente número da Revista Calundu de 2020, o qual se dedicaria a "Mães de Santo e Mulheres de Terreiro", conforme chamada de contribuições amplamente divulgada desde o início deste ano. Guilherme também concordou com a ideia e Patrícia aceitou o desafio, que ganhou o formato de uma entrevista sobre o tema, em especial sobre a relação de suas entidades com suas filhas de santo, como se apresenta no terceiro texto desta seção especial, que se tornou ainda mais especial por se tratar de pessoas diretamente implicadas com a chamada do periódico. Patrícia também considerou a proposta como uma boa oportunidade de dar voz às suas filhas, para que elas mesmas falassem mais a respeito e, assim, lhe provocasse ir adiante em seus pensamentos. 
Desse modo, Kaira Wollo, Skadi Wollo e Skuld Wollo, três filhas do terreiro e da mãe de santo, sendo as duas primeiras também suas filhas biológicas, escreveram em coautoria um ensaio sobre suas experiências com todas as entidades femininas (quiçá também feministas, em lato sensu) recebidas por Patrícia, conforme estão aqui manifestas no texto seguinte, no idioma original. Esse ensaio foi visto por Guilherme, que as convidou para a referida publicação.

Cabe dizer ainda que a entrevista com Patrícia foi feita a partir de um conjunto de perguntas iniciais, elaborado por Guilherme. Ela o respondeu por meio de várias mensagens de áudios e escritas ${ }^{4}$, de modo intertextual com o ensaio das filhas, em um ambiente de pensamento coletivo, próprio da experiência comunitária dessa tradição religiosa. O conteúdo foi organizado e editado por Guilherme e Tânia, posteriormente revisado pela própria Patrícia, ganhando a forma final em sua língua materna e em seu estilo particular de autoria narrativa.

Com muita honra, disponibilizamos este material, que traz interessantes e profundas reflexões. Agradecemos a colaboração das filhas de santo e, em particular, da Mãe Patrícia, que gentil e generosamente se sentiram interpeladas por nossa proposta, fazendo-a também delas. Que todos/as envolvidos/as neste esforço, assim como os/as leitores/as, tirem o melhor proveito dos registros que se seguem, podendo alçá-los a patamares mais complexos e superiores do (auto)conhecimento e da riqueza que as religiões afro-brasileiras nos oferecem.

\section{Referências bibliográficas}

BAJA, Maria Azul di. "Um Relato Kimbandista, Umbandista e Batuqueiro da Argentina". Revista Calundu, v.3, n.2 - jul-dez, 2019. Disponível em: https://periodicos.unb.br/index.php/revistacalundu/article/view/27167/24725. Acessado em 07 de maio de 2020.

NOGUEIRA, Guilherme Dantas. "Na minha casa mando eu" - mães de santo, comunidades de terreiro e o Estado. Tese (Doutorado em Sociologia) - Departamento de Sociologia, Instituto de Ciências Sociais. Universidade de Brasília. 2019.

Recebido em: 10/05/2020

Aceito em: 14/05/2020

\footnotetext{
${ }^{4}$ Os áudios foram transcritos a texto com o apoio da afrorreligiosa cubana Angélica M. Rivera López, apoiadora do Grupo Calundu. Externamos a ela nosso agradecimento.
} 